DOI: 10.2478/ausfm-2019-0022

\title{
Performativity and Worldmaking.
}

\author{
Interview with Chiel M. Kattenbelt
}

\section{by Ágnes Karolina Bakk ${ }^{1}$}

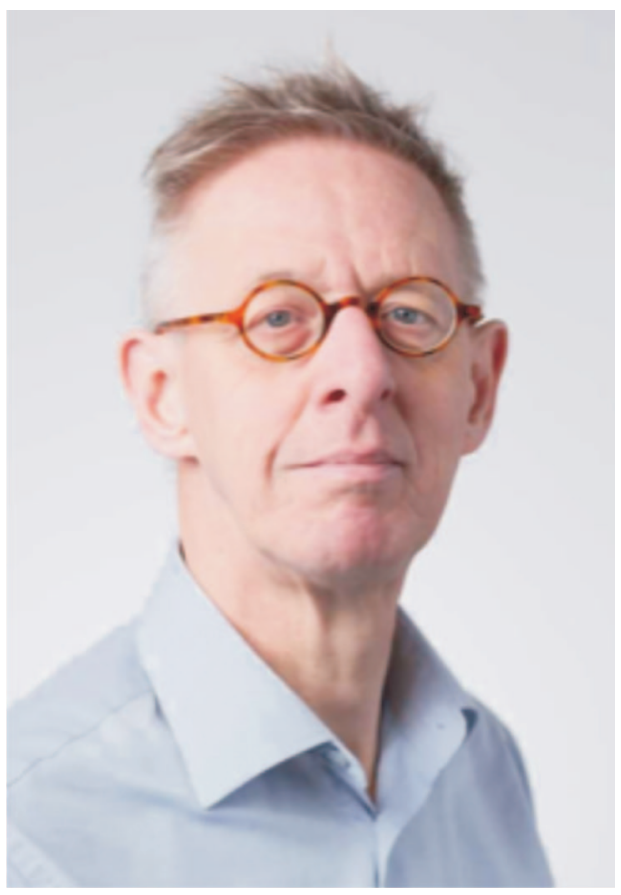

You are Associate Professor in Media Comparison and Intermediality at Utrecht University, author and editor of several books and chapters related to the concept of intermediality, but lately you also started to develop a special VR installation, Hamlet Encounters, together with Eric Joris and other professionals. Can you tell me a bit more about it and its context?

The VR installation Hamlet Encounters is part of a larger project in which we try to find out what we can do with new technologies in live performances. In the case of Hamlet Encounters we are experimenting with virtual reality and motion capture. We try to combine these technologies, wondering what we can do with these and what these can do with us. In our practice as research project we primarily focus on the performative aspects of the media we use: how do media redefine our sense, play in the sense of affecting our senses, how can we make media also playful in the way we use them for building worlds, for staging, for self-referencing and self-reflecting?

1 This interview was made within the framework of the Exploratory Research Project Rethinking Intermediality in Contemporary Cinema: Changing Forms of In-Betweenness, PN-III-IDPCE-2016-0418, funded by a grant of the UEFISCDI (Executive Unit for Financing Higher Education, Research, Development and Innovation), Romania. 
Why do you use Hamlet for this special purpose?

The practice as research project Hamlet Encounters stages and simulates Hamlet's world as a world out-of-joint. My contribution to the project is inspired by Harold Bloom's analysis of Hamlet in Shakespeare: The Invention of the Human, in which he argues that the scope of Hamlet as a character is much broader than the story in which he appears. There are good reasons to consider the character as the first modern mind on the European stage, who by his return from Wittenberg to Elseneur is thrown back from an emerging modern world into medieval times, who wouldn't doubt to revenge his father's assassination, but not without reflecting on the moral implications of such a violent act. We might conceive Hamlet as the director of the play, who challenges with his behaviour all the other characters while wondering what it means to act ethically in a highly conflicted world. Hamlet's soliloquies are the key moments in the play's development.

The world of our own times could also be considered as a world-out-of-joint, as a conflicted world, in particular politically (the rise of populism), economically (the rise of protectionism) and ecologically (the issue of climate change).

Let's turn toward a more technical aspect of Hamlet Encounters. Can you share with us some challenges about the process of adapting Hamlet to this special VR experience?

In Hamlet there is a scene in which Hamlet instructs actors to perform a play with the intention of unmasking his father's murderer. This scene gave us the idea that Hamlet could be considered as the director of the entire play, who behaves as he does in order to see how the others react to it, which he then reflects on. Hamlet could be considered as the first modern mind on the European stage. The most important moments in the play are Hamlet's soliloquies in which he is thinking, not so much wondering or doubting what to do as rather reflecting on the implications and consequences of what he is supposed to do. We took Hamlet's thinking mind as starting point for our project. How can we use the new technologies in such a way that we construct all kinds of possible worlds as "mind spaces" - rather than worlds that seem to exist on their own - in order to find out how these might relate to one another?

Now that you mention possible worlds, do you think that VR will find its own story or right format of narrative or something else? 
Yes, I think so. I prefer to speak in terms of possible worlds rather than stories or narratives. The new technologies we are talking about, play, perform and participate with, are way more about making worlds than telling stories in a narratological sense. In how we play, perform and participate by means of using new technologies like VR and motion capture, we not only construct in new ways all kinds of possible worlds, but also find new ways of addressing and positioning its users in relation to these worlds and by consequence of how they experience these. VR technology has so far been mainly considered as a kind of new form of film which goes one step further: you are no longer a disappearing invisible witness like in mainstream film, who is allowed to be everywhere in the world in order to understand what the film is about, but you are actually in the centre of it. Of course, you pay the price for it, because the first thing you notice in the virtual space is that your body has disappeared. "Where am I?" "Where is my body?" You immediately sense how your eyes and ears are redefined, and then you have to find out with your physical body how to relate to it.

Do you think that the medium of $V R$ is closer to the cinematic medium, or rather to video games or to performing arts?

Compared to film, VR is so much something completely different. Film (art) is all about making choices with regards to frame, perspective and distance, about the relation between the movements of images and the movements in images, and consequently about the positioning of the spectator, who needs to identify with the eye of the camera in order to orient him- or herself in a spatial totality which is not actually given but constructed in the spectator's own imagination. The more the spectator has to rely on his/her own imagination, the more he/she experiences the imaginary space as being in it, surrounded by it, albeit usually that's to say in mainstream film, as an invisible witness.

The dynamics provided by the film's possibility to change frame, perspective and distance could be conceived as blurring the boundaries between time as the structuring principle of after-each-other and space as the structuring principle of next-to-each other. In the movement in or of images we perceive a temporalization of space - the passing by of time is visible - and in the alteration of spaces a spatialization of time - the awareness or assumption of the simultaneity of two relatively independent actions or events taking place in different or at least separated spaces. There is also a need for film to change frame, perspective and distance in order to neutralize the slowing down of the experienced duration of 
time as a result of looking through a camera eye. In other words: changing frame, perspective and distance is all about the dynamics of focalization more or less, like jumping in time and/or space is all about memory and imagination.

Quite different from watching a film on a screen is wearing a head-mounted display which visually disconnects the spectator from the physical space around $\mathrm{him} /$ her like in the case of omnidirectional or $360^{\circ}$ video and virtual reality. As already said, but coming back to this: by wearing goggles, the eyes are so radically redefined that it immediately affects the proprioception of the body in an attempt to relate to and connect with a space which is literally untouchable, even more so since the body itself seems to have (all of a sudden) disappeared. In the case of omnidirectional video, the position of the spectator in the video space is fixed, whether it be in a single, Archimedean point in space from where s/he can look around in all directions or moving through that space according to a pre-recorded trajectory, whether or not while actually moving or being moved with his/her own body synchronously through the space.

In the case of virtual reality, the position of the perceiver is no longer fixed. The surrounding space is a space in which s/he can actually move around and maybe even interact with, in the sense that s/he can actually do something in order to make something happen or at least to explore its borders. The perceiver is the one who actually navigates through and interacts with the space. What s/he actually sees and maybe even hears is fully determined by real-time and corporeal movements of the perceiver in and maybe even through space by means of motion tracking, whether or not equipped with controllers.

This sense of agency and the real-time rendering is similar to what we can experience in performing arts, with the concept of "liveness," no?

Absolutely yes. You have to negotiate all the time when you use these technologies in the live performance. How do you deal with the actual event as it takes place in the here and now? Where do you use the technologies for the sake of bridging the gap between where you are and somewhere else? Or, how do you use the technologies by creating a kind of friction between the virtual space where you seem to be, although your body has disappeared, and the physical space where you actually are and even still in touch with? I have seen several VR projects as part of the annual Cinedans festival in Amsterdam last year (2018) made by choreographers who are used to start from the physical body. Many of them tried to bring the body of the immersant in play again by literally 
addressing his or her sense of touch. In a way, being in a virtual world could evoke an intensified corporeal experience ... and isn't the sense of being present pre-eminently a matter of liveness when it really relates to the physical body?

I have recently read an interview with the director Tsai Ming-liang. ${ }^{2}$ He directed a 360-degree movie that premiered at the Venice Biennale in 2017 and he said that directing a 360-degree movie is like directing a theatre performance.

It might be that Tsai Ming-liang relates with his comparison between $360^{\circ}$ video and theatre in particular to the specific conditions under which a production is made: for example, in the sense that you need to take it all in one take, although from a central position within, which is quite different from the proscenium arch theatre and its characteristic frontality. Of course, theatre can take place in any physical space and I guess we all know many examples of live performances which are all but structured according to the frontality of the proscenium arch theatre or the model of the fourth wall through which we may observe what seems to happen independently from our presence. We might even think of performances where the spectator is actually surrounded by the physical space (like in the case of omnidirectional video) which belongs to the presented space in the performance, where the distinction between stage and auditorium is or seems to be blurred or only constructed by a mental frame or by a technological device that might function as such.

There is also a certain chaos in the taxonomy of VR productions. There are people making $V R$ films, there are VR experiences, installation works with integrated VR-experiences...

I noticed this too. There is much confusion about what virtual reality actually is. That is why I make a clear distinction between VR and omnidirectional video, in which the space is more or less fixed from where the image is scanned or recorded. Within that space your position is fixed, too, and in so far as you move that's a result of the recording or rendering but not specifically related to the navigating moving body in that space. You follow more or less the movement as it has been decided already by the modality how it was recorded, whereas

2 Zhou-Ning Su: Tsai Ming-liang on Confronting Death in 'The Deserted' and the Future of Virtual Reality. The Film Stage, 8 September 2017, https://thefilmstage.com/features/tsai-ming-liangon-confronting-death-in-the-deserted-and-the-future-of-virtual-reality/ Last accessed 02. 08. 2019. 
in the case of a virtual space you are in a digitally constructed world in which you really interact with your environment: you can walk around and do several things in order to make something happen. For me that is quite a fundamental difference, and the basic concepts that I use in order to find out how a virtual reality relates to $360^{\circ}$ video and how it relates to film, or to theatre. But then you can start to wonder: how does the frame function? How does the distance function? How does the perspective function?

Considering that last time we met was last year at Intermediality Now: Remapping In-Betweenness Conference organized by the Department of Film, Photography and Media of Sapientia Hungarian University of Transylvania, in Cluj, Romania, how do you see the concept of intermediality in the framework of theatre and performance studies today?

Intermediality is very much the experience of all of us living in a highly mediatized culture and society. I prefer to start from the concepts of play, perform, and participate: we use all these technologies for all these activities. We are also more than ever aware that all these technologies and media are what they are and how they relate to one another makes sense in the network of media by which we are more and more surrounded. With regard to live performance, I think that the technologies are interesting in trying to find out how you can negotiate and deal with the fact that you have to structure time and space and maybe also in a way escape from the absolute presence of the here and now. There you can learn from these technologies where you can update them and make them relevant. As you can see, in the installation Hamlet Encounters we've made it in a way that not only the illusion is visible, but the creation of the illusion as well. Technologies are relevant for making all kinds of frictions, disruptions, create uncertainties about what you actually perceive: you have to negotiate all the time with your body and see how you can relate to what you hear and what you see. So, the relevance is very much related to the way technologies play our senses and how in particular theatre as a kind of hypermedium provides a stage for other media to be staged, not just for the sake of what they might present, but also for reflecting on them, on how they are used in other domains in our culture and society. In my view the most interesting applications of new media technologies are those that also really teach us about the specificity of these technologies. 
In 2010, you defined intermediality "as a specific mode of performativity." How do you see the current state and relationship of performativity and the new world building strategies (even by including new media works into this process)?

In 2010, by this definition I claimed that performativity is an inherent quality of all arts. It refers to "worldmaking," "staging," "self-reference" and "self-reflexivity." In making worlds, art works primarily relate to the modality of the possible rather than the actual, they are presentations rather than representations. A possible world is conceived as being made by an "auctorial instance" - auctorial understood according to the broad spectrum of meanings of the Latin word auctor, which ranges from witness and author(ity) to designer and builder. A possible world can be presented from three idealtypically distinguished positions and orientations. From a dramatic position, a possible world is presented in such a way that it seems to exist on its own, as an absolute world outside which, strictly speaking, nothing exists. From a lyric position, the auctorial instance places itself as an experiencing subject in the centre of the possible world which it constructs. From an epic position, the auctorial instance presents itself not as an experiencing subject inside, but as a considering "subject" outside the possible world, which is on the one hand its object of construction and on the other its object of reflection.

An artwork primarily refers to that which it brings into existence. It consists of performative utterances, it is in its ideal-typical form a performance, an event presented for an audience. A basic feature of any performance or performative situation is ostension, which implies that staged objects, bodies, actions and events are disposed of their contingencies (Eco 1977), they become intentional signs, that is to say, "signs of signs" rather than "signs of objects" (Bogatyrev 1971).

Because of its worldmaking and staging aspect, a performance by definition refers to and reflects on itself and on the event in which the performance occurs. Being a presentation rather than a representation, a performance incorporates, to put it paradoxically, its own context. What the performance presents becomes meaningful within an internal coherence of reference - even if this coherence seems to be denied by fragmentation - within a worldmaking referential density. Self-reference and self-reflexivity are not only to be considered characteristics of the performance, but also of the perceiver who takes up the position of a spectator, who fulfils the function of an audience. Being a performer and a spectator implies a kind of double consciousness, since both are aware that they are there for each other, the one presenting or staging him- or herself while the 
other is looking on. I consider the aesthetic turn in the arts as the arts' answer to the performative turn in contemporary culture and society at large, as I mentioned in one of my papers in 2018 (Kattenbelt 2018), in particular is - as far as this turn occurs as a mediatization or instrumentalization of culture and society - for the sake of efficiency in the case of management, effectiveness in the case of technology, and efficacy in the case of cultural performances (with reference to Lyotard 1979 and McKenzie 2001).

New and new media entertainment genres are arising and one can often notice that it is hard to define them but one can approach them from the medium of cinema or theatre. What do you think, can we still talk about the concept of medium specifity especially in the case of these "older" media?

Each medium is always to a certain extent - that is to say, not exclusively determined by how it frames and (literally) puts into perspective that which it presents, by how it positions and addresses its audience, by how it facilitates specific affordances in terms of suggestions or clues as how to use the medium, in particular its material properties, and by how it provides specific modes of agency, acknowledging that even perceiving itself is already a matter of performing (Rotman 2008). In comparison with film, theatre is often reductively conceived as proscenium arch theatre, that's to say as a three-dimensional physical space/ stage strictly separated from the auditorium. This space/stage is perceived by the spectator within a fixed frame as a spatial totality. Each individual spectator has a fixed seat or pitch in the auditorium, which implies that perspective and distance from which the stage is perceived are fixed as well.

The history of film is often treated as the film's emancipation from the frontality of theatrical modes of presentation. From this perspective, film should liberate itself from theatre in several respects in order to develop its own language. By alternating camera positions and moving the camera, the frontality of theatre can easily be broken through. The dynamics of cinema requires flexibility in perspective and distance. Close-ups obviate the need for stylization and exaggeration in acting. Artificial spaces should be replaced by natural sites. Of course, theatre can take place in any physical space, and I guess we all know many examples of live performances which are all but structured according to the frontality of the proscenium arch theatre or the model of the fourth wall through which we may observe what seems to happen independently from our presence. We might even think of performances where the spectator is actually surrounded by the physical space which belongs to 
the presented space in the performance, where the distinction between stage and auditorium is or seems to be blurred or only constructed by a mental frame or by a technological device which functions as such.

Do we have to develop new media consumption strategies because our senses are engaged in a multimodal way? What is your opinion, how does this affect us on psychological level?

Change is a necessary condition for perception since - strictly speaking - our senses are only capable of perceiving differences, which implies that each percept is relative. Receiving sensory data via our senses, the bodily (reflex) actions and reactions connected to these data - which implies besides differentiation also (adaptive) synchronization - as well as their conceptual processing are inextricably linked. What we experience is not just the result of a physiological process determined by the distinctive capacities of our senses and developed neurological skills, but also a matter of complex interactions of the brain and body as they are guided by reflexive and adaptive actions, routines, habits and interests. Nothing is what it is just by itself or on its own, but always related to a specific orientation. Each orientation could be characterized by a specific interest as it relates to a specific kind of behaviour and action connected with specific claims of validity. The aesthetic orientation is - as I already mentioned - primarily related to making experiences for the sake of a creative reflection on one's own experience. In short: perception is always related to change as a tensional relationship between distinguishing and synchronizing. Thanks to routines, habits and interest-driven attention, we are usually hardly aware of how the whole body is actually involved in perception and experience. Since art in its "event-ness" is all about making experiences for the sake of creative reflection, its strategies are usually aimed at alienation, de-automation, in short in breaking through routines and habits, but always in such a way that we can still relate to and connect with what we perceive and experience, which is crucial for meaningful making sense. 


\section{References}

Bloom, Harold. 1998. Shakespeare: The Invention of the Human. New York: Riverhead Books.

Bogatyrev, Pjotr. 1971 [1938]. Les signes du théâtre [The Signs of the Theatre]. Poétique vol. 8: 517-530.

Eco, Umberto. 1977. Semiotics of Theatrical Performance. The Drama Review vol. T73: 107-117.

Kattenbelt, Chiel. 2018. Intermedial Theatre in a Mediatized Culture and Society. In Intermedial Performance and Politics in the Public Sphere, ed. Katia Arfara, Aneta Mancewicz and Ralf Remshardt, 15-26. Cham, Switzerland: Palgrave MacMillan.

Lyotard, Jean-François. 1979. La Condition Postmoderne: Rapport sur le Savoir [The Postmodern Condition: A Report on Knowledge]. Paris: Éditions de Minuit.

McKenzie, Jon. 2001. Perform or Else: From Discipline to Performance. London and New York: Routledge.

Rotman, Brian. 2008. Becoming Beside Ourselves: The Alphabet, Ghosts, and Distributed Human Beings. Durham, NC: Duke University Press. 